\title{
Gavi-"La Caixa": Una alianza de éxito a favor de la vacunación infantil
}

Diego Arias Padilla Joan Fontrodona

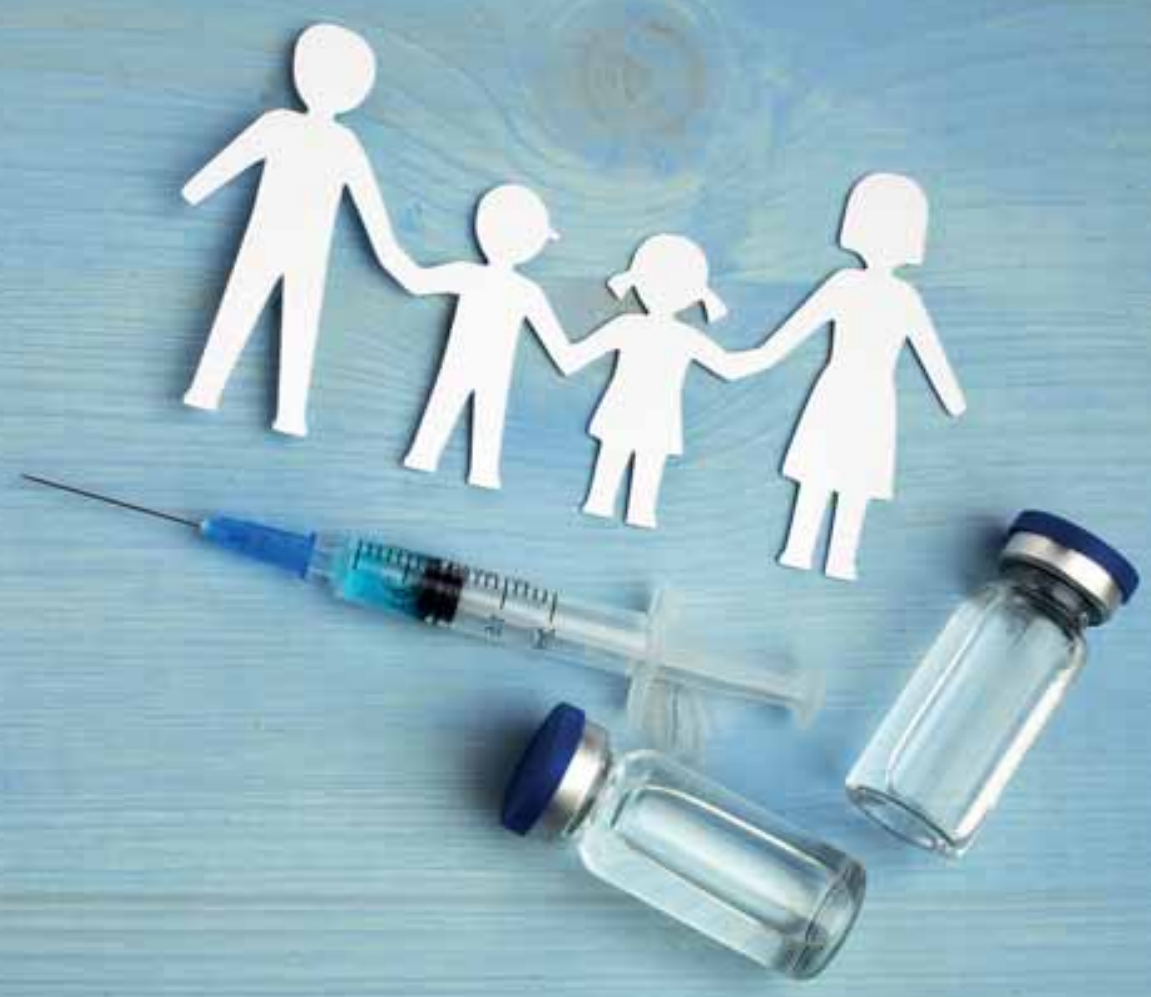

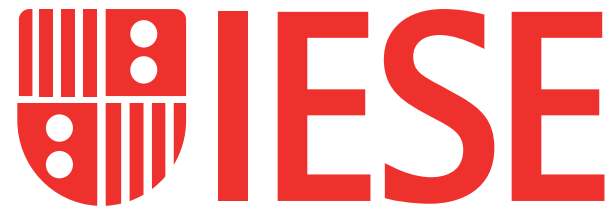

Business School University of Navarra
BILL $\circlearrowleft$ MELINDA GATES foundation

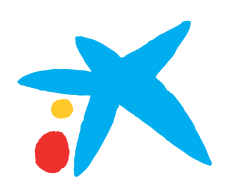

"la Caixa" Foundation 


\section{Gavi-"la Caixa": Una alianza de éxito a favor de la vacunación infantil}

\section{Diego Arias Padilla}

Candidato a doctorado en el IESE Business School.

\section{Joan Fontrodona}

Profesor de Ética Empresarial y Análisis de Situaciones de Negocio en el IESE Business School. 
Gavi: la alianza para la vacunación $\quad 4$

Origen y desarrollo $\quad 4$

Los socios de Gavi 5

El modelo de Gavi 7

Fundación "la Caixa" $\quad 8$

Orígenes de "la Caixa" 8

$\begin{array}{ll}\text { La Obra Social } & 10\end{array}$

La alianza Gavi-“la Caixa”: 12 años de aportaciones sostenibles 11

El inicio de la alianza 11

El inicio de la colaboración (2008-2010) 12

La participación innovadora de Banca de Empresas (2011-2014) 13

La entrada de Banca Privada y la comunicación del Matching Fund (2015-2018) 15

$\begin{array}{ll}\text { Retos para el futuro } & 17\end{array}$

$\begin{array}{ll}\text { Conclusión: las guías para una donación sostenible } & 18\end{array}$

$\begin{array}{ll}\text { Anexos } & 20\end{array}$ 


\section{Introducción}

“La Caixa” es un socio estratégico nuestro para la lucha por la inmunización infantil junto con Gavi, The Vaccine Alliance. Destaco principalmente sus ganas de ir más allá del simple hecho de firmar un cheque, el compromiso de su alta dirección y su poder de convocatoria".

Estas fueron las palabras de Joe Cerrel cuando hizo referencia a la importancia que tiene "la Caixa" para la Fundación Bill y Melinda Gates en la lucha por la inmunización infantil. Joe Cerrel, director general, responsable de Políticas Globales y de Apoyo a Causas de la Fundación Bill y Melinda Gates, ha participado en primera persona en el proceso de involucración de "la Caixa" con Gavi, una colaboración que ha generado más de 31 millones de euros en aportaciones en el periodo de 2008 a julio de 2019 y que ha logrado vacunar a más de 5,4 millones de niños en los países más pobres de América del Sur y África ${ }^{1}$.

Gavi es una iniciativa que respondió a la llamada de una cumbre organizada en 1998 por el Banco Mundial que congregó a la Organización Mundial de la Salud (OMS), UNICEF, académicos, ministros de Salud, agencias internacionales y miembros de la industria farmacéutica para responder a una pregunta simple, pero que albergaba inmensos desafíos: ¿cómo empezar a proporcionar vacunas a los niños que más las necesitan? Seis meses después, la Fundación Bill y Melinda Gates lanzó el "reto Gates", que buscaba soluciones innovadoras para superar las barreras que impiden que millones de niños reciban las vacunas básicas necesarias. En 1999 se convocó una segunda cumbre que intentaba responder a este reto. Como resultado de esa reunión, los principales protagonistas mundiales para la inmunización decidieron trabajar juntos en una alianza, que recibió el nombre de Global Alliance for Vaccines and Immunization (Gavi). Finalmente, en noviembre de ese mismo año la Fundación Bill y Melinda Gates se comprometió a financiar durante cinco años a Gavi con una donación de 750 millones de dólares. El lanzamiento formal de Gavi tuvo lugar durante la reunión del Foro Económico Mundial en Davos (Suiza) en enero de 2000.

Desde el inicio de sus actividades, Gavi ya innovaba con distintos modelos de financiamiento. Había desarrollado con éxito el modelo de la International Finance Facility for Immunization (IFFIm), que utiliza donaciones de largo plazo de gobiernos donantes para vender la inmunización de bonos en el mercado de capitales y lograr grandes cantidades de donaciones para Gavi. Otro modelo de financiamiento era el de la Corporación Financiera Internacional (IFC, por sus siglas en inglés), con su sociedad de gestión de activos (AMC, por sus siglas en inglés), a través del Banco Mundial. La AMC moviliza e invierte capital en compañías sostenibles de mercados emergentes con retornos atractivos y con un alto impacto social. Precisamente dentro de ese ambiente de innovación es donde "la Caixa" se une a Gavi, The Vaccine Alliance 2.

"La Caixa" firmó su primer compromiso con Gavi en 2008 con cuatro millones de euros, que fue, en ese año, la mayor cantidad aportada por una entidad privada a Gavi, lo que la convirtió en el primer socio privado de Gavi hasta ese momento. En el mismo año "la Caixa” lanzó la Alianza Empresarial para la Vacunación Infantil con el objetivo de dar la oportunidad de sumarse a la lucha contra la mortalidad infantil a las empresas, como parte de su responsabilidad social; a los clientes de Banca Privada, como una propuesta de filantropía y mecenazgo, y a los empleados y a la sociedad en general, a través de microdonativos.

Lo novedoso del papel de aquella Alianza -más allá de las contribuciones realizadas por "la Caixa"- es haber logrado desarrollar un proceso en el cual dichas donaciones provienen no solo de la institución, sino de la implicación de otras partes interesadas, por ejemplo, sus empleados, empresas, clientes y particulares interesados en esta causa solidaria.

\footnotetext{
${ }^{1}$ Gracias a la aportación del Matching Fund, que es una estrategia realizada por “la Caixa” y la Fundación Bill y Melinda Gates. Más adelante se explicará en detalle esta estrategia y otras que fueron clave en el éxito de este caso.

${ }^{2}$ Para más información, véase www.iffim.org y www.ifcamc.org.
} 
El objetivo de este caso es describir cómo "la Caixa" logró poner en marcha este programa como un proceso para conseguir fondos mediante la implicación de la entidad financiera, los empleados y sus clientes, para que sirva de ejemplo como una buena práctica de responsabilidad social y pueda ser imitado por otras organizaciones. El resto del ejemplo que trataremos se estructura del modo siguiente: primero, realizaremos una breve descripción de Gavi, explicando su modelo de negocio y de asociación; después, nos centraremos en "la Caixa", comenzando con una breve descripción de su historia y detallando a continuación las distintas etapas de su participación en Gavi desde 2008; finalmente, presentaremos unas conclusiones y una lista de propuestas que puedan ser reproducidas por otras organizaciones que se planteen llevar a cabo iniciativas similares de apoyo a proyectos de contenido social.

\section{Gavi: la alianza para la vacunación}

\section{Origen y desarrollo}

Gavi, The Vaccine Alliance, fue creada formalmente en el año 2000 con la misión de "salvar la vida de los niños y proteger la salud de las personas mediante el incremento del uso equitativo de vacunas en países de ingresos bajos". Fue Nelson Mandela quien contribuyó a mejorar la salud de las personas más desfavorecidas cuando se dirigió a los jefes de Estado de los países donantes instándoles a apoyar los esfuerzos para extender los beneficios de la vacunación a todos los niños.

Gavi desarrolló un modelo innovador de inmunización, que se inició con la participación de los Gobiernos de seis países donantes: Estados Unidos, Reino Unido, Noruega, Suecia, Países Bajos y Dinamarca, y con un compromiso de 750 millones de dólares, otorgados por la Fundación Bill y Melinda Gates ${ }^{3}$.

El objetivo no era simplemente la financiación para el acceso a las vacunas, sino aprovechar la experiencia de los miembros de la Alianza - la Fundación Bill y Melinda Gates, UNICEF, la Organización Mundial de la Salud y el Banco Mundial- para implantar una propuesta más asequible, disponible y sostenible de acceso a las vacunas. Por ello, la fase final del programa culmina cuando el país en desarrollo puede pagar, distribuir y aplicar las vacunas por sí mismo.

La estrategia de Gavi ha seguido hasta ahora cuatro fases y, actualmente, se encuentra diseñando la quinta. La primera (2000-2005) se concentró en conseguir fondos para ampliar rápidamente el alcance y la calidad de los programas de inmunización en los 75 países más pobres. La segunda fase (2006-2010) fue un periodo de innovación y grandes cambios, en el que Gavi se centró en fortalecer los sistemas de distribución de la inmunización de manera sostenible; acelerar la adopción y el uso de vacunas infrautilizadas y de nueva creación, mejorando la seguridad de suministro; incrementar la previsibilidad y la sostenibilidad del financiamiento a largo plazo, y aumentar y evaluar el valor de la alianza a través de la mejora de la eficiencia, el aumento de la promoción y la innovación continua. En la tercera época (2011-2015) se desarrolló la hoja de ruta para la implantación de las vacunas pentavalentes, en particular, las vacunas del neumococo y el rotavirus. Se formalizaron los objetivos estratégicos bajo los siguientes criterios: vacunas, sistemas de salud, aspectos financieros y modelado del mercado, para darle forma.

\footnotetext{
${ }^{3}$ La aportación de la Fundación Bill y Melinda Gates a Gavi asciende para el periodo 2016-2020 a un total de 1.556,4 millones de dólares. Ello supone el $18,6 \%$ de todas las donaciones recibidas por Gavi.
} 
Actualmente estamos en la cuarta fase (2016-2020), que tiene entre sus objetivos: acelerar la captación equitativa y la cobertura de las vacunas; incrementar la efectividad y la eficiencia de la administración de las mismas como parte de un sistema de salud fortalecido; mejorar la sostenibilidad de los programas nacionales de inmunización, y dar forma a los mercados de vacunas y a otros productos de inmunización. La quinta fase (2021-2025), aprobada por el Consejo de Gavi en junio de 2019, trabajará para establecer la equidad como principio organizador; conseguir una mayor diferenciación en el apoyo de los proyectos hechos a medida de los países; hacer hincapié en la demanda, las comunidades y el género; fortalecer la aproximación para una programación sostenible; poner mayor atención en la prevención y la respuesta ante epidemias, y fomentar la innovación. La aprobación y el lanzamiento de la nueva inversión necesaria se presentó en la 7th International Conference on African Development (TICAD), que tuvo lugar en Tokio en agosto de 2019.

Además, el marco estratégico incluye ocho principios que definen las características del modelo de negocio de Gavi: que esté liderado por el país que recibe las vacunas, que requiera la implicación de la comunidad, que esté globalmente comprometido, que sea catalizador y sostenible, a la vez que integrador, innovador, colaborativo y responsable. Claramente, podemos observar cómo el modelo de Gavi trasciende la mera financiación de vacunas: se trata de un programa integral donde el financiamiento de las vacunas es un medio para un fin mayor.

Los resultados de Gavi son muy convincentes. En menos de 20 años de existencia ha logrado prevenir 13 millones de muertes en el ámbito de la inmunización, vacunar a más de 760 millones de niños (66 millones solo en 2018), fortalecer los sistemas de salud y los servicios de inmunización en 75 países e introducir más de 430 vacunas hasta 2018. Los resultados en el ámbito financiero son igualmente destacables. El retorno de la inversión de Gavi es de 21 dólares por cada dólar gastado debido al ahorro en costos de salud, de salarios y de pérdida de productividad a causa de enfermedad. Sin embargo, si tenemos en cuenta los beneficios de tener personas que viven más sanas y son más longevas, el retorno aumenta hasta los 54 dólares por dólar gastado; se han generado más de 150.000 millones de dólares en beneficio económico en el periodo entre el 2000 y el 20174, y para 2025 se espera generar alrededor de 100.000 millones de dólares de beneficio económico producto de la prevención de enfermedades, muertes y discapacidades permanentes. Además, el objetivo es llegar a 2025 con 300 millones más de niños vacunados, lo cual supone aproximadamente un total de 22 millones de muertes prevenidas 5 . Hasta el momento, 15 países que han participado en el programa han logrado la transición hasta estar en condiciones de gestionar el programa de inmunización por sí solos ${ }^{6}$.

\section{Los socios de Gavi}

El patrón de negocio de Gavi se inicia con su modelo de alianzas. Aprovecha las ventajas comparativas de su asociación público-privada para maximizar el impacto que tendrían juntos en comparación con el resultado obtenido si cada uno de sus aliados abordara la inmunización por separado ${ }^{7}$. Dentro de la Alianza destacan en primer lugar cuatro organizaciones mundiales que han venido liderando la lucha por la inmunización desde sus ámbitos de acción: UNICEF, el Banco Mundial, la Organización Mundial de la Salud (OMS) y la Fundación Bill y Melinda Gates. Gavi se apoya en las tres primeras de manera distinta para conseguir realizar un trabajo focalizado en cada país; es decir, la actuación de Gavi se centra directamente en los países a los que ayuda. Sin embargo, la Alianza no se encuentra físicamente en cada país, sino que ofrece su especialización en el tema de las vacunas a través de la OMS, que trabaja directamente con los ministros de Salud correspondientes. Por otra parte, Gavi proporciona la financiación para que UNICEF realice la adquisición de las vacunas. Finalmente, el Banco Mundial ofrece consejos estratégicos para dinamizar el mercado de capitales, por lo que se convierte en un actor clave en la innovación relacionada con modelos de financiamiento que Gavi diseña para promover las colaboraciones.

\footnotetext{
${ }^{4}$ https://www.gavi.org/about/mission/facts-and-figures/.

${ }^{5}$ https://www.gavi.org/library/news/press-releases/2019/gavi-sets-ambitious-goal-to-immunise-300-million-people-by-2025-leaving-no-one-behind/.

${ }^{6}$ https://www.gavi.org/about/mission/facts-and-figures/.

${ }^{7}$ Fuente: https://www.gavi.org/about/partners/the-partnership-model/.
} 
La aportación de la Fundación Bill y Melinda Gates a la Alianza es de suma importancia. Fueron ellos quienes hicieron una primera donación para que Gavi pudiera iniciar sus actividades; sin embargo, la implicación de dicha Fundación es incluso anterior a esta aportación. Recordemos que Gavi nació como una respuesta al "reto Gates" y, a medida que Gavi fue realizando sus operaciones, la Fundación Gates continuó donando a la institución. En 2019 la aportación total realizada por la Fundación asciende a más de 5.000 millones de dólares ${ }^{8}$. Su implicación no se limita exclusivamente a donaciones financieras. La Fundación promueve descubrimientos innovadores en la industria farmacéutica, desde el desarrollo de nuevas vacunas hasta el proceso de distribución de las mismas. De este modo, por cada aportación que Gates realizaba, Gavi daba pasos de gigante hacia la inmunización infantil. Actualmente, la Fundación tiene un asiento permanente en el Consejo de Gavi, junto con los tres socios mencionados previamente. El Consejo (Figura 1) -que se compone de 28 miembros- cuenta con representantes de gobiernos de países donantes (5), de gobiernos de países en desarrollo (5), de la industria de vacunas en países en desarrollo (1), de la industria de vacunas en países industrializados (1), de organizaciones de la sociedad civil (1), de institutos de investigación en salud (1), de la Organización Mundial de la Salud (1), de UNICEF (1), del Banco Mundial (1) y de la Fundación Bill y Melinda Gates. Además del presidente del Consejo (1) de Gavi y del CEO de Gavi (1), hay otros nueve miembros a título individual que no cuentan con una afiliación profesional a Gavi, pero que pueden aportar desde sus distintas especialidades.

Figura 1. Miembros del Consejo de Gavi

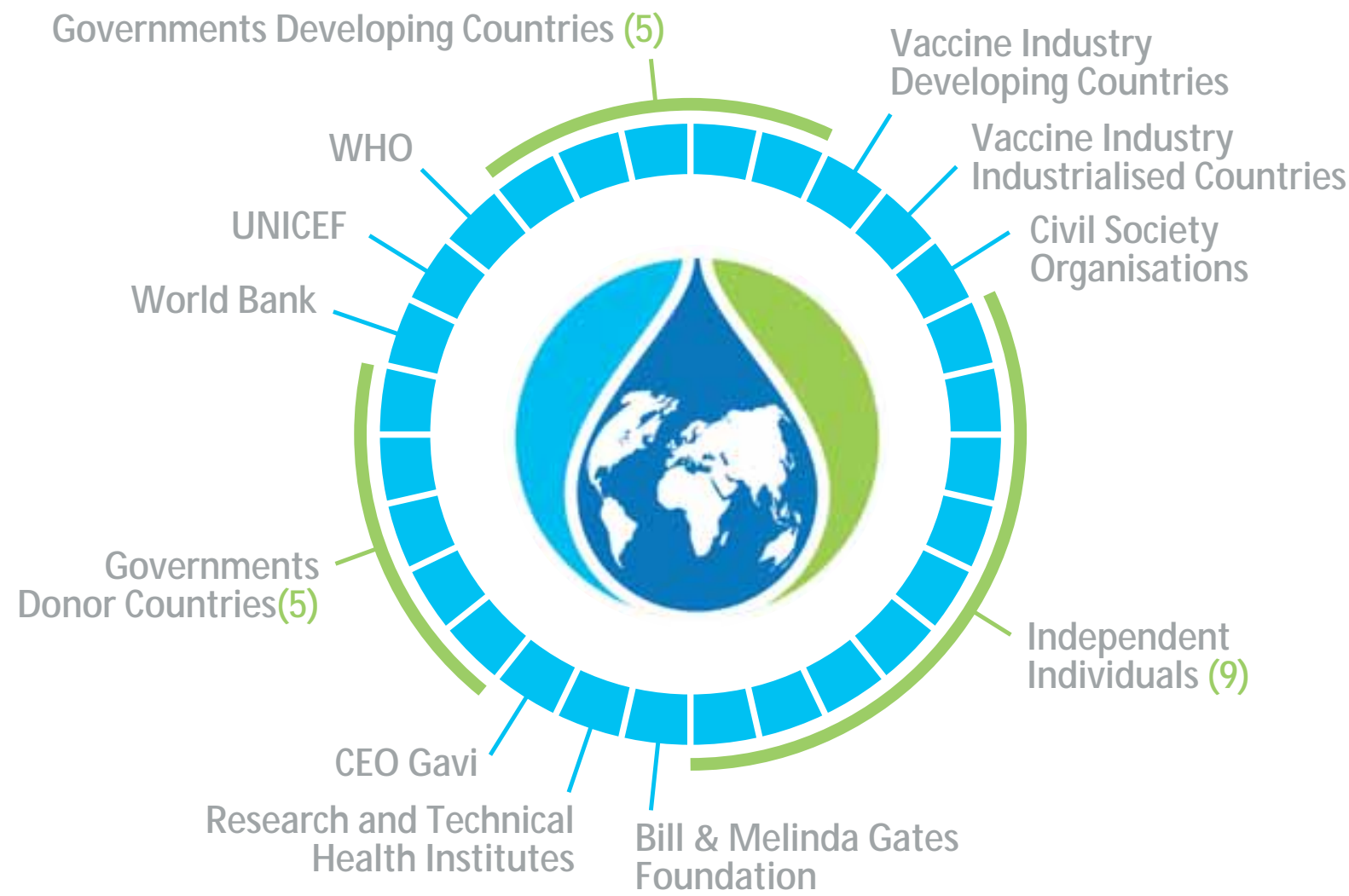

Fuente: www.gavi.org, https://www.gavi.org/our-alliance/governance.

${ }^{8}$ Fuente: https://www.gavi.org/investing/funding/donor-profiles/bmgf/. 


\section{El modelo de Gavi}

El modelo de negocio de Gavi refleja su misión a través de seis pasos (Figura 2):

1. Aprovechar al máximo las economías de escala incorporando en la demanda de vacunas a los países más pobres del mundo y enviando, de este modo, una señal clara a los fabricantes de las mismas.

2. Asegurar la financiación a largo plazo. Todos los países en los cuales Gavi participa contribuyen también a la financiación para la adquisición de las vacunas. Conforme el país va mejorando y sus ingresos se incrementan, aumenta asimismo su contribución dentro de la cofinanciación. Por lo tanto, su financiación no es permanente, sino que se gestiona de tal manera que al final el país pueda valerse por sí mismo.

3. Influir en el mercado de vacunas. De este modo, los fabricantes podrán planificar mejor su producción y proveer vacunas adecuadas a un precio asequible.

4. Acelerar el acceso de los niños de países pobres a las vacunas, mejorando las tradicionales y ayudando a introducir otras nuevas, apoyándose en la fuerza de su modelo de negocio.

5. Mejorar y fortalecer el sistema de salud y de inmunización de los países a los cuales se brinda apoyo, fortaleciendo las plataformas de entrega de las vacunas.

6. Conseguir la inmunización sostenible. El modelo de Gavi culmina cuando el país al cual se le ha brindado apoyo puede gestionar por sí solo su sistema de inmunización.

El patrón de ayuda de Gavi no es asistencialista: se trata de un modelo de ayuda pensado y ejecutado para que, con el transcurso del tiempo, deje de ser necesario; es decir, el proyecto tiene un inicio y se espera que tenga un final. Precisamente durante ese proceso es cuando Gavi actúa, acompañando al país donde la ayuda se está prestando para que, poco a poco, sea capaz de ejecutar su propio programa de inmunización. La misión de Gavi se cumple cuando ya no se le necesita más. Como comentaron los colaboradores de Gavi en la sede de Ginebra: "Nosotros acompañamos hasta que el país esté listo para su graduación".

\section{Figura 2. Modelo de negocio de Gavi}

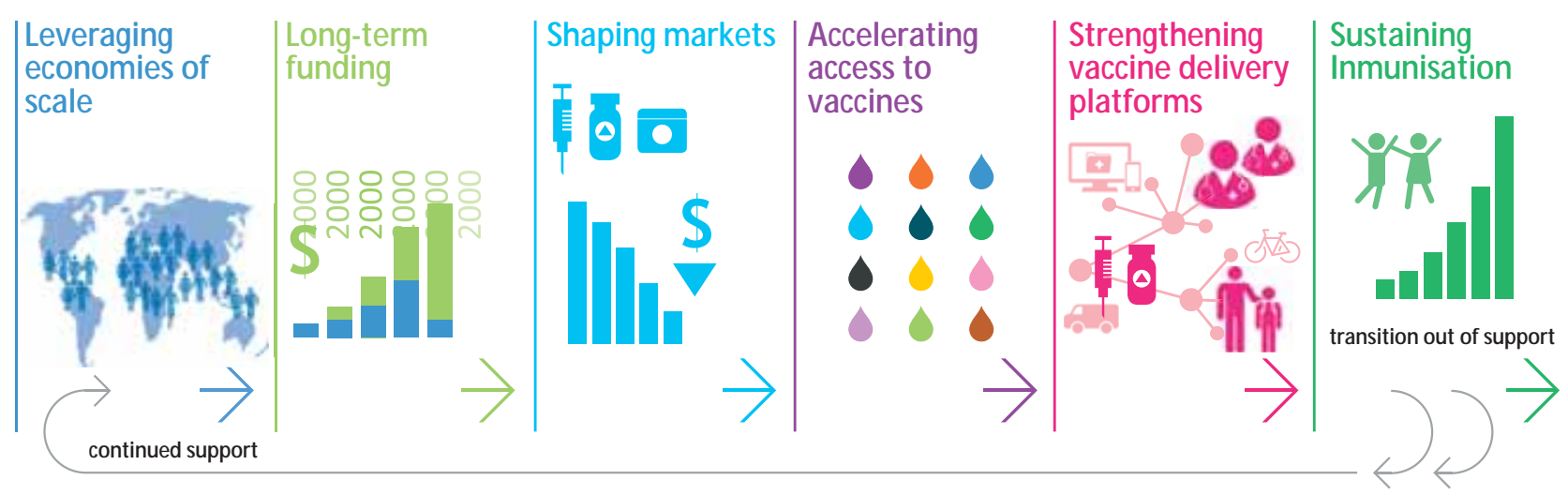

Fuente: Documento proporcionado por Gavi. 


\section{Fundación "la Caixa"}

\section{Orígenes de "la Caixa"}

Los orígenes de "la Caixa" se remontan a principios del siglo XX en Barcelona, cuando Francesc Moragas, quien también fue su primer director general ${ }^{9}$, creó la Caja de Pensiones para la Vejez y Ahorros. En 1902 se declaró en la ciudad una huelga general sin precedentes desencadenada por las duras condiciones que soportaban los obreros. Fue reprimida de manera cruda por la policía con un balance trágico de muertos y heridos. Esta realidad le reveló a Moragas, sabio observador de la sociedad de su tiempo, que era necesario implantar un sistema de ayuda y previsión social que armonizara la sociedad. Para ello, hizo un llamamiento en los diarios para que los cuidadanos aportaran dinero para los heridos y las familias de los fallecidos. De sobrar una cantidad, como ocurrió, se utilizaría para crear una caja de pensiones pensada para el futuro de los obreros. Este fue el origen, el 5 de abril de 1904, de la Caja de Pensiones para la Vejez y Ahorros. Durante los primeros años, "la Caixa" tuvo un desarrollo vigoroso. Hacia 1920, en solo 16 años, la entidad se convirtió en la primera caja de ahorros de Cataluña y de España. Las miras altruistas de Moragas impulsaron en 1918 una nueva estructura dentro de "la Caixa", que se denominó Obra Social. Hasta ese momento los excedentes de "la Caixa" se destinaban a reservas y donativos a diferentes entidades benéficas; sin embargo, a partir de ese año la institución decidió formalizar su misión social creando un órgano que asumiera la gestión de su ayuda social de modo profesional. Como ámbitos de acción se determinaron la salud, la igualdad y la cultura. A la muerte de Moragas, en 1935, "la Caixa" contaba con 109 oficinas y una cuota de mercado del 59,5 \% de los depósitos de las cajas catalanas. El crecimiento continuó en las siguientes décadas. En el cronograma de la Tabla 1 se ofrece un resumen de los hitos de crecimiento más importantes de "la Caixa"..

\section{Tabla 1. Hitos de "la Caixa"}

\begin{tabular}{|l|l|}
\hline Año & Evento \\
\hline 1904 & Francesc Moragas crea "la Caixa”. \\
\hline 1913 & Se expande a las Islas Baleares. \\
\hline 1918 & Se crea la Obra Social. \\
\hline 1935 & Fallece Francesc Moragas. \\
\hline 1955 & Se inician las actividades inmobiliarias con carácter social. \\
\hline 1969 & Se convierte en la primera entidad bancaria de Europa en introducir el teleproceso. \\
\hline 1975 & Es una de las primeras instituciones en lanzar las tarjetas de crédito en España. \\
\hline 1979 & Se implantan los primeros cajeros automáticos. \\
\hline 1981 & Se inaugura el Museo de la Ciencia en Barcelona. \\
\hline 1983 & Se reestructura la Obra Social y se crea la Fundación “la Caixa”. \\
\hline 1989 & La entidad integra en su estructura el negocio de GrupCaixa. \\
\hline 2000 & Se fusiona con la Caja de Ahorros y Monte de Piedad de Barcelona. \\
\hline 2002 & Se constituye CaixaHolding. \\
\hline 2008 & Se inaugura CaixaForum. \\
\hline 2010 & Se adquiere la división de Banca Privada de Morgan Stanley en España. \\
\hline 2011 & Se fusiona con Caixa Girona. \\
\hline 2014 & "La Caixa" traspasa su negocio bancario a Criteria, que, a su vez pasa a ser un grupo bancario denominado \\
\hline Caixanank, que posteriormente sale a bolsa. \\
\hline ahorros y fundaciones bancarias. \\
\hline 190 .
\end{tabular}

${ }^{9}$ Para más información sobre la creación de "la Caixa" y el rol de Francesc Moragas, véase https://www.iese.edu/wp-content/uploads/2019/01/ Cuadernos-Catedra-CaixaBank-ST-0497.pdf. 
A partir del año 2000 se dieron cambios en la regulación de las cajas en España. En particular, la Ley de cajas de ahorros y fundaciones bancarias, del 27 de diciembre del 2013, tuvo una influencia importante en la estructura organizativa de "la Caixa". En junio de 2014, la Fundación "la Caixa" se liquidó y traspasó todo su patrimonio a la Fundación Bancaria "la Caixa", que seguía teniendo el control de todos los negocios financieros a través de CriteriaCaixa, además de quedarse con el $40 \%$ de las acciones de CaixaBank. Ante este nuevo panorama existía el riesgo de la que la Obra Social desapareciera, como sucedió con las obras sociales de muchas otras cajas de ahorro de España que siguieron un proceso parecido en esos años. Sin embargo, se decidió elevar la Obra Social al nivel de la Fundación Bancaria y, actualmente, está anexada a esta ${ }^{10}$. La Figura 3 muestra el organigrama actual.

Figura 3. Organigrama de "la Caixa"

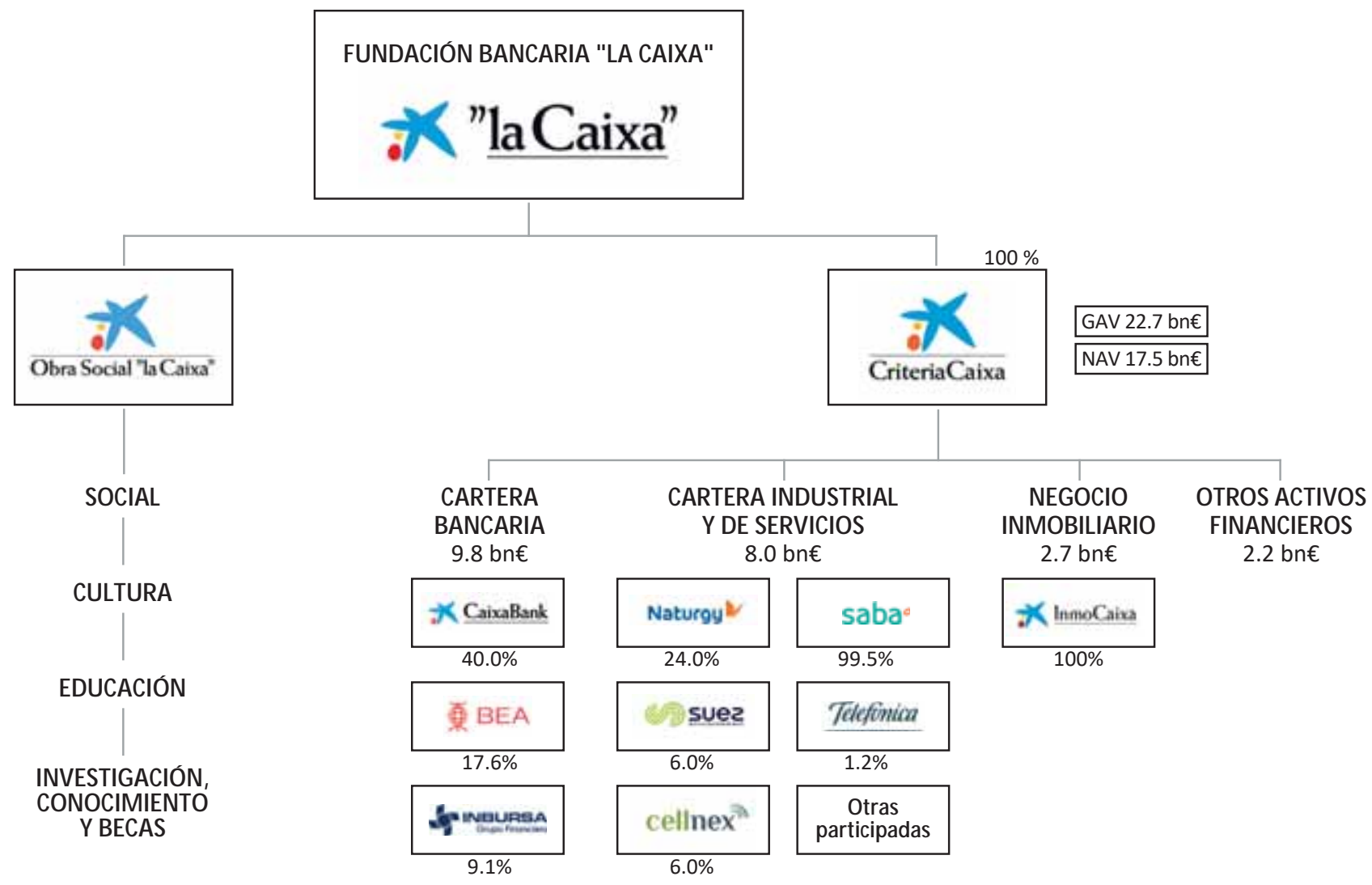

Fuente: Documento proporcionado por la Fundación "la Caixa".

${ }^{10}$ En el común denominador de los ciudadanos siempre se ha conocido la institución como "la Caixa". Por ello, a efectos de este caso, seguiremos refiriéndonos a la institución como "la Caixa". 


\section{La Obra Social}

La Obra Social está gestionada directamente por la Fundación Bancaria "la Caixa” y ha mantenido un presupuesto anual sostenido de 500 millones de euros desde 2007, que en 2019 se incrementó a 545 millones de euros. Creada en 1918, ha mantenido una actividad continuada en el tiempo, dentro y fuera de España. La misión de la Obra Social es la de "construir una sociedad mejor y más justa, que dé más oportunidades a las personas que más las necesitan". La actividad de la Obra Social se concentra actualmente en cuatro ámbitos: carácter social, investigación, cultura y educación, y sus acciones se basan en los principios de subsidiariedad, sentido de anticipación, concentración de esfuerzos, flexibilidad y alcance.

El Área Internacional de la Obra Social se ocupa de proyectos de alcance global. Su cometido es crear oportunidades y luchar contra las desigualdades de los colectivos más vulnerables en países de África, Asia y América Latina a través de programas que contribuyan a la consecución de los Objetivos de Desarrollo Sostenible establecidos por las Naciones Unidas ${ }^{11}$, trabajando en alianza y colaboración con entidades de referencia. En palabras de su directora, S.A.R. la infanta doña Cristina, "la consolidación de alianzas globales siempre ofrece resultados más eficientes que la suma de acciones puntuales. La suma de esfuerzos por parte de todo tipo de agentes, públicos y privados, permite optimizar resultados y logros".

Los principales proyectos y actividades del Área Internacional se concentran en empleo, educación, salud global, y emergencias y ayudas humanitarias. También gestiona alianzas estratégicas con organismos internacionales tales como la AGA Khan Foundation, la Fundación Bill y Melinda Gates, el Comité Internacional de la Cruz Roja, ACNUR, UNICEF, el Council on Foundations, la Calouste Gulbenkian Foundation, Development Alternatives y MED Confederation Impact 2030, entre otros.

Además del proyecto de vacunación infantil, el Área Internacional, con una larga experiencia en temas de cooperación, gestiona otros programas. Entre ellos cabe destacar "Work 4 progress", que fomenta el empleo de jóvenes y mujeres de India, Perú y Mozambique; el programa "MOM- Plan de innovación para la malnutrición infantil (ACNUR)", que contribuye a la lucha para la supervivencia infantil en campos de refugiados y comunidades de acogida, mejorando las condiciones nutricionales de niños menores de cinco años, y "Cooperantes Caixa", un programa de voluntariado corporativo internacional que ofrece asistencia técnica en proyectos de cooperación internacional a empleados del Grupo “la Caixa”, entre otros.

\footnotetext{
${ }^{11}$ En septiembre de 2015, más de 150 jefes de Estado y de Gobierno se reunieron en la histórica Cumbre del Desarrollo Sostenible en la que aprobaron la Agenda 2030. Esta Agenda contiene 17 objetivos de aplicación universal que, desde el 1 de enero de 2016, rigen los esfuerzos de los países para lograr un mundo sostenible en el año 2030. Estos nuevos objetivos instan a todos los países a adoptar medidas para promover la prosperidad, al tiempo que protegen el planeta.
} 


\section{La alianza Gavi-“la Caixa”: 12 años de aportaciones sostenibles}

\section{El inicio de la alianza}

Desde la creación de su programa de Cooperación Internacional en 1997, la Fundación "la Caixa” priorizaba la mejora de la salud global entre sus líneas estratégicas y colaboraba en iniciativas de lucha contra las principales enfermedades que afectan a la pobreza, como la malaria, el sida, la tuberculosis y la neumonía.

En esa línea, en 2005, aprovechando un viaje a Mozambique de la directora del Área Internacional, S.A.R la infanta doña Cristina, el doctor Pedro Alonso, entonces director del CRESIB (Centro de Investigación en Salud Internacional de Barcelona), organizó una reunión con Nelson Mandela y Graça Machel, principales impulsores y fundadores de Gavi, junto con la Fundación Gates. Fruto de este encuentro fue la celebración de un simposio que tuvo lugar en Barcelona, en el que participaron reconocidos expertos nacionales e internacionales para abordar los principales retos de la salud mundial, entre los cuales la inmunización era clave. En el marco de este evento se anunció el ingreso del Gobierno de España en Gavi, con el compromiso de donar nueve millones de euros en 20 años.

En 2008 se produjo un segundo viaje a Mozambique. En esta ocasión el presidente de "la Caixa”, Isidro Fainé, y su director general, Jaume Lanaspa, visitaron junto a la directora del Área Internacional los programas que la entidad estaba implementando en el país, entre ellos, el Centro de Investigación de Salud de la ciudad de Manhiça, fundado por el doctor Pedro Alonso.

En ese mismo año tuvo lugar el segundo simposio sobre la reducción de la mortalidad infantil, en el que el presidente de "la Caixa" confirmó el compromiso de la entidad para prevenir la mortalidad infantil y cooperar en la inmunización infantil con Gavi.

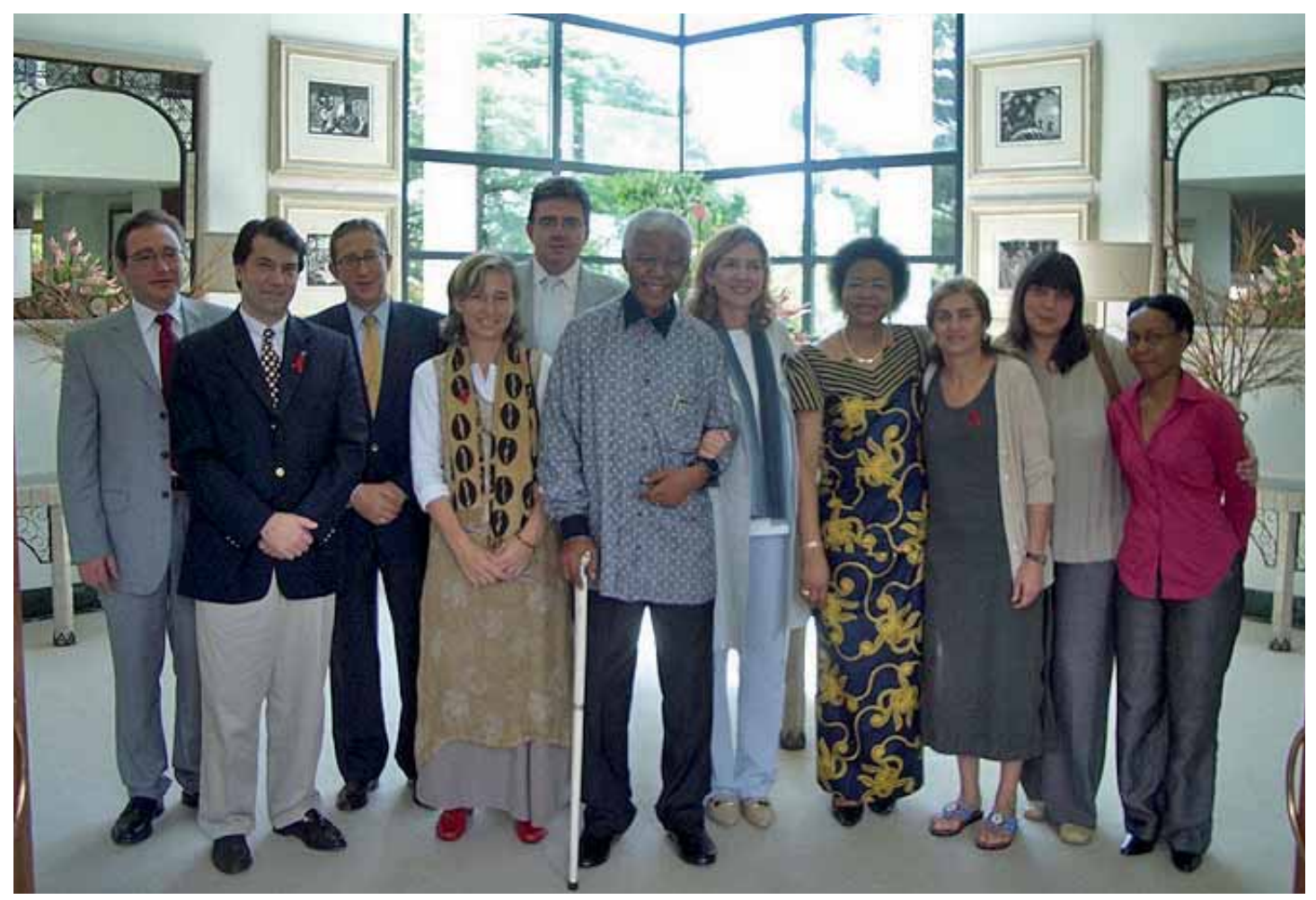

S.A.R. la infanta doña Cristina junto con Nelson Mandela, Graça Machel y la delegación de "la Caixa" en Mozambique en 2005.

Fuente: Documento proporcionado por la Fundación "la Caixa". 


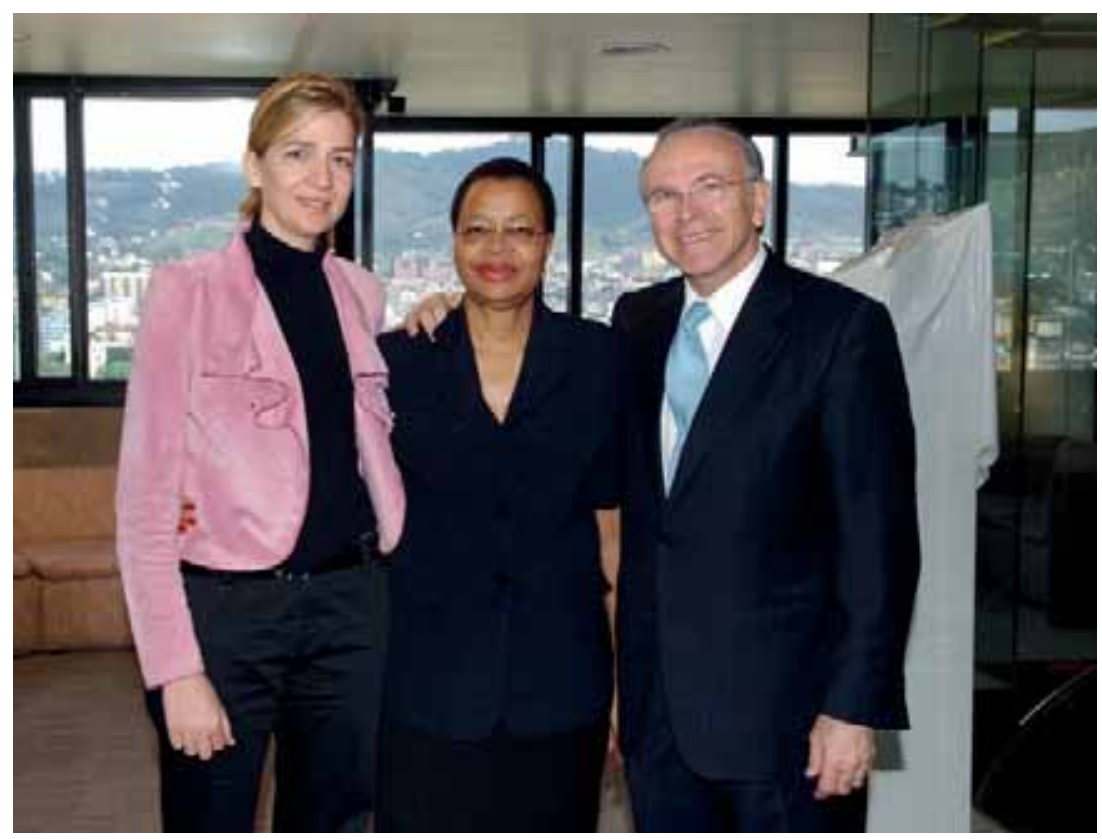

S.A.R. la infanta doña

Cristina (directora del

Área Internacional,

Fundación "la

Caixa”), Graça

Machel (presidenta

del Consejo de

Gavi) e Isidro Fainé

(presidente de

"la Caixa") en el

lanzamiento de

la Alianza para la

Vacunación Infantil en

2008 en Barcelona.

Fuente: Documento

proporcionado por la Fundación "la Caixa".

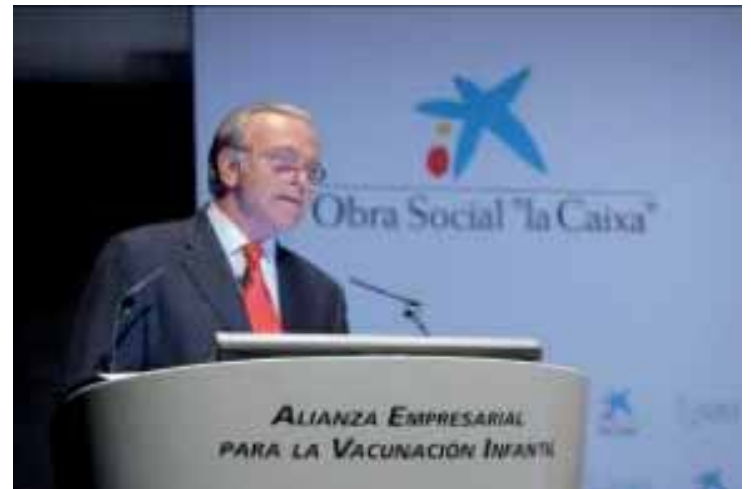

El presidente de "la Caixa", Isidro Fainé, reafirmó el compromiso de la entidad con la vacunación infantil en Barcelona en 2008.

Fuente: Documento proporcionado por la Fundación "la Caixa”.

"La Caixa" se comprometió a realizar una donación inicial de cuatro millones de euros. No obstante, el compromiso de Isidro Fainé iba más allá y su idea era aprovechar la extensa red de oficinas, la cartera de clientes y el prestigio y la imagen de actor social que tenía la entidad financiera para convertirse en un catalizador de aportaciones en España. El objetivo era sumar esfuerzos y abrir la posibilidad de recaudar aportaciones por parte de sus empleados y clientes, además de servir como plataforma para aquellos individuos e instituciones que deseasen realizar contribuciones, aunque no tuvieran un vínculo comercial directo con "la Caixa".

En los 12 años de colaboración entre "la Caixa" y Gavi cabe señalar tres fases: el inicio de la colaboración, la participación innovadora de Banca de Empresas, y la entrada de Banca Privada y la comunicación del Matching Fund.

\section{El inicio de la colaboración (2008-2010)}

Como se ha dicho, la implicación de "la Caixa" se proponía ir más allá de la aportación inicialmente comprometida de cuatro millones de euros. El reto era grande, porque se pretendía promover la colaboración en una iniciativa sin retorno económico. "La Caixa” lanzó en 2008 la Alianza Empresarial para la Vacunación Infantil con el objetivo de ofrecer a las empresas españolas, como parte de su responsabilidad social, la oportunidad de colaborar con el proyecto de Gavi en la lucha contra la mortalidad infantil. La iniciativa se abrió también a los clientes, a los empleados del Grupo "la Caixa" y a todas las personas solidarias que quisieran contribuir a salvar la vida de los niños. "La Caixa" garantizaba que todas las aportaciones se destinaban íntegramente a la vacunación infantil. 
La entidad desarrolló un sistema de reconocimiento por las aportaciones recibidas en cuatro categorías a partir de 500 euros: colaborador, plata, oro y platino. Se trata de un conjunto de materiales y pautas de comunicación para la difusión del proyecto. En todos los casos, estas donaciones tienen derecho a las deducciones fiscales correspondientes según la ley en vigor. Las categorías de plata, oro y platino reconocían la condición de miembro de la Alianza para la Vacunación Infantil y otorgaban el derecho a usar un sello y material personalizado como prueba de pertenecer a la Alianza. Además, en las categorías de oro y platino se ofrecía al cliente la posibilidad de visitar la sede de Gavi en Ginebra y de participar en actos internacionales de alto nivel organizados por la Alianza.

La donación anual de "la Caixa" provenía de la aportación realizada directamente por la entidad financiera y del importe recaudado de distintas partes interesadas (empleados, clientes de Banca de Empresas y particulares). Por parte de "la Caixa", la colaboración de cuatro millones de euros se repitió en 2009 y se rebajó a tres millones de euros en 2010. Asimismo, las cantidades recaudadas por la entidad siguieron una tendencia decreciente. En 2008 el número de empresas que realizaron aportaciones fue de 95, mientras que en 2009 ese número disminuyó un 35\%. En 2008 el total de particulares fue de 52; no obstante, el siguiente año ese número decreció también un 27\%. Esta tendencia se repitió en 2010, cuando las empresas aportadoras disminuyeron un $58 \%$ y el número de particulares, un $29 \%$. Sin embargo, el número de colaboraciones de empleados de "la Caixa" en 2009 creció un 105\%, de 269 en 2008 a 550, y, en 2010, un $32 \%$, hasta alcanzar las 727 aportaciones. Ello refleja el compromiso de los colaboradores de "la Caixa" con el reto lanzado por el presidente de la entidad en 2008, a pesar de ser un periodo de crisis. Las aportaciones que provenían directamente de "la Caixa" constituían el grueso de la cantidad otorgada a Gavi. Sin embargo, los importes recaudados sufrieron una disminución tanto en el número de aportaciones como en su monto total (de 288.771 euros en 2008 a 214.332 euros en 2010, lo que supone una disminución del 26\%) ${ }^{12}$.

Ante estos resultados "la Caixa" ya estaba pensando en introducir cambios para fortalecer su estrategia de recaudaciones, más aún cuando lo previsto era que la aportación directa de "la Caixa" disminuyese en los siguientes años hasta quedar en un millón de euros como cantidad fija. La institución seguía comprometida con Gavi, pero el Área Internacional, que gestionaba las colaboraciones, necesitaba proponer maneras mejores y más eficientes de recaudar aportaciones entre los clientes de "la Caixa". Fue en este momento cuando Banca de Empresas adoptó un rol importante en la Alianza y se convirtió en la protagonista de la siguiente fase, que abarca del 2011 al 2014.

\section{La participación innovadora de Banca de Empresas (2011-2014)}

Banca de Empresas es la división de CaixaBank que da servicio a compañías que facturan más de dos millones de euros. Cuenta con un equipo especializado de 1.200 profesionales en gestión de empresas y dispone de 125 centros de empresas en España. Además, la entidad cuenta con una red de oficinas en el extranjero para dar respuesta a aquellas empresas que tengan negocios internacionales. En la búsqueda de una rentabilidad sostenible y una gestión coherente con los valores corporativos de calidad, confianza y compromiso social, Banca de Empresas ha mantenido durante los últimos años la idea de ser un referente en gestión responsable y compromiso con la sociedad. En este contexto es donde sus responsables entendieron el valor que el proyecto con Gavi podía aportar a su acción comercial y apostaron decididamente por él, haciendo que el programa tomase un nuevo impulso.

Banca de Empresas había estado involucrada en el proyecto desde su inicio. No obstante, en la primera fase no se obtuvieron los resultados esperados. En esta primera etapa se contaba con un mensaje y una estrategia de comunicación para que los gestores pudieran ofrecer a sus clientes la colaboración en este proyecto, pero el reto era complicado por la novedad que suponía incorporar un discurso distinto con los clientes. Si se quería incrementar el número de aportaciones, debía incorporarse este programa como parte del portafolio de productos y servicios de la cartera, dándole la misma importancia y peso a Gavi que al resto de soluciones financieras. Así, la estrategia fue equiparar las aportaciones realizadas a la Alianza con algunos aspectos de los productos financieros que ofrecían los gestores y directores de Banca de Empresas.

\footnotetext{
${ }^{12}$ Los datos numéricos pueden verse en la Tabla 2 del Anexo.
} 
Luis Cabanas, el máximo responsable de Banca de Empresas, decidió impulsar el programa Gavi comunicándolo personalmente en las reuniones de equipo a partir de 2009, proponiendo que todos los empleados obtuviesen, como mínimo, una aportación de una empresa de su cartera de clientes. Poco a poco Gavi pasó a tener un papel destacado dentro de las presentaciones del Comité de Banca de Empresas, unas reuniones con los directores de empresas de las zonas territoriales donde se ponía especial interés en los datos y el seguimiento del negocio. En estos comités se incluía periódicamente un apartado en el que se preguntaba sobre las aportaciones a Gavi y se analizaba cómo conseguir un mayor número de ellas y un mayor importe; también se pedía a los asistentes la propuesta de nuevos métodos e ideas para la captación de más empresas. Ana María Rovira, actual directora de Desarrollo de Negocio de Banca de Empresas y responsable de impulsar el proyecto Gavi en Banca de Empresas desde 2012, afirma que el programa Gavi es tan importante como el resto de los productos financieros ofrecidos a sus clientes: "La comunicación del programa Gavi a nuestros clientes debía tener la misma importancia y prioridad que cualquier otro producto de nuestra cartera. Por eso era crucial incluirlo en nuestro día a día, en las visitas a los clientes, en nuestro discurso con las empresas". Los responsables de Banca de Empresas estaban convencidos de que ofrecer este tipo de programas permitía a CaixaBank diferenciarse de otras entidades y dar valor añadido a la relación con sus clientes.

Así pues, Gavi se consolidó como un producto más en Banca de Empresas, con un seguimiento periódico de los objetivos y un reconocimiento a los gestores y directores en la captación de aportaciones. Banca de Empresas ponía todo su esfuerzo en que todos los empleados conocieran el programa para que pudieran transmitirlo a sus clientes. Así lo explica también el director ejecutivo de Banca de Empresas, Luis Cabanas: "El mensaje que queríamos transmitir era el de ser un banco diferente, ser referentes en gestión responsable y compromiso con la sociedad. Por eso, como aliciente, se decidió llevar a cabo durante las convenciones anuales de Banca de Empresas un reconocimiento especial a los centros y gestores con el mayor número de aportaciones, invitándoles a que compartieran sus métodos, tácticas y estrategias de captación de aportaciones".

Como parte de este reconocimiento, se invitaba a los gestores y directores de Banca de Empresas que habían conseguido el mayor número de aportaciones a realizar un viaje de campo para visitar aquellos territorios donde las vacunas que habían conseguido gracias a sus aportaciones estaban salvando millones de vidas. Los primeros viajes de campo fueron a Nicaragua y Mozambique, y resultaron experiencias muy gratificantes y motivadoras para los empleados de CaixaBank.

También se dio a empleados y a diferentes empresas la oportunidad de visitar in situ la sede de Gavi en Ginebra. El viaje a la ciudad suiza contemplaba varias instancias de formación donde se podía conocer el programa, los avances científicos en inmunización, su impacto social y su situación financiera. Además, podían conversar directamente con los involucrados en la Alianza, desde científicos que trabajaban para el desarrollo de nuevas y mejores vacunas, hasta analistas financieros que supervisaban el día a día de las aportaciones recibidas. De esta forma, los colaboradores que visitaban Ginebra regresaban a España con un mayor sentido de pertenencia e identificados con la labor de salvar la vida de niños en países pobres. Estos mismos gestores hacían de prescriptores con el resto de los empleados animándolos a ofrecer este tipo de iniciativas a sus empresas clientes. Rosa Bretones, personal de apoyo y gestora de Banca de Empresas en la sede de CaixaBank en Almería, comentaba orgullosa que "CaixaBank no es solamente un banco, ya que ofrece distintas oportunidades a sus clientes para comprometerse en proyectos sociales como Gavi y crear así un vínculo especial entre ellos y la entidad". Como resultado de estas acciones, se obtuvo un gran impacto en la captación de aportaciones de clientes nuevos y recurrentes por parte de los gestores y directores. En datos, el número de empresas subió en dos años (2011-2013) de 35 a 161, lo que incrementó el aporte en euros de 228.750 a 361.250; sin embargo, en 2014 las aportaciones cayeron un 23\%. El número de empleados que realizaban aportaciones se mantuvo en una media de 740 personas anuales durante el periodo 2011-2014. Por otra parte, tal y como estaba previsto, la aportación realizada directamente por "la Caixa" se redujo a dos millones en 2011 y 2012, para luego quedar fijada en un millón a partir de 2013.

Además de las acciones llevadas a cabo desde Banca de Empresas, en 2014 se inició una campaña de microdonaciones, es decir, pequeñas donaciones de un alto número de personas a través de la web o de las oficinas de CaixaBank. Como resultado, las aportaciones totales de "la Caixa", sin contar la aportación directa, pasaron de 278.068 euros en 2011 a 457.691 euros en $2014^{13}$. Sin embargo, era necesario seguir trabajando en la elaboración de nuevas estrategias para incrementar la recaudación y el número de aportaciones, tanto de empresas que habían participado anteriormente como de nuevas. En ese momento es cuando se produjo la entrada de Banca Privada.

\footnotetext{
${ }^{13}$ El detalle de las aportaciones directas y recaudadas de "la Caixa" puede verse en la sección de Anexos al final del caso, en las Tablas 2 y 3 . Además, se han incluido tres gráficos ilustrativos de la tendencia de las donaciones en las Figuras 6,7 y 8
} 


\section{La entrada de Banca Privada y la comunicación del Matching Fund (2015-2018)}

Banca Privada es el servicio de CaixaBank que atiende las necesidades de los clientes que cuenten con un patrimonio mínimo de 500.000 euros. Entre los servicios que ofrece se encuentra la asignación de un gestor personal que acompaña al cliente en la gestión de su patrimonio. En 2015 se creó el departamento de Filantropía dentro de Banca Privada, con el objetivo de dar respuesta a las inquietudes y necesidades de sus clientes en materia de filantropía e inversión socialmente responsable. Era un segmento distinto pero que ofrecía grandes oportunidades en lo que a la Alianza se refiere. Dentro del departamento de Filantropía se decidió que, además de ofrecer a los clientes el diseño de proyectos solidarios a medida, se les facilitaría también la alternativa de un proyecto de filantropía ya existente y que pudieran apoyar. Tras analizar el abanico de iniciativas que se ejecutaban desde la Obra Social, Banca Privada decidió ofrecer a sus clientes la Alianza para la Vacunación Infantil. La decisión se fundamentó en la solidez y la transparencia del programa, así como en el apoyo de la Fundación "la Caixa” y de la Fundación Bill y Melinda Gates al mismo.

El cliente de Banca Privada era distinto al cliente de Banca de Empresas, por lo que la aproximación al mismo debía ser también distinta. Los gestores de Banca Privada utilizaban las reuniones de negocio con sus clientes para mencionar la Alianza, pero siempre advirtiéndoles de la diferencia de lo que se les iba a ofrecer y marcando una distancia con los productos financieros que se venían discutiendo. Por ello, los gestores decidían primero a quién iban a ofrecer la Alianza, basándose en si el cliente tenía o no la empatía necesaria hacia los temas sociales y haciendo referencia a la Obra Social y la historia de la Caixa. Esto era de vital importancia: identificar qué clientes tenían la sensibilidad adicional para querer sumarse a la Alianza. Luego, los gestores de Banca Privada tenían que hacer notar las fortalezas de la Gavi.

Es este momento cuando la solidez del socio adquiere importancia. No son pocos los comentarios en los que se destaca que la decisión de cerrar la aportación se dio básicamente por el hecho de que "la Caixa" estaría detrás del proyecto, junto con la Fundación Bill y Melinda Gates. La presencia de ambas fundaciones generaba confianza en los clientes de Banca Privada y la solidez que estas dos entidades aportaban era de vital importancia para ellos.

Desde hacía un tiempo, la dirección del Área Internacional venía solicitando a Gavi un requisito que se estimaba fundamental. Para reforzar la confianza que le tenían sus clientes, "la Caixa" consideraba necesario informar a los donantes sobre el destino de las aportaciones que esta venía realizando. La petición fue difícil de conseguir, no porque Gavi rechazara realizar ese informe, sino más bien por la idea de elaborar un informe específico de las aportaciones de un socio privado. Gavi realizaba informes anuales extremadamente detallados y auditados para mantener la claridad y la transparencia de sus cuentas. Sin embargo, la actividad de Gavi se nutría de un presupuesto único, en el cual no se distinguía el origen de los fondos recibidos. Por el contrario, para reforzar sus aportaciones, "la Caixa" necesitaba contar con el detalle de cómo las aportaciones que se venían realizando eran usadas efectivamente para la aplicación de vacunas en países pobres del mundo. Finalmente, Gavi encontró el modo de redactar el informe, dando a la entidad financiera un instrumento adicional para poder generar mayores recaudaciones. Este detalle no es menor, ya que los clientes de Banca Privada y "la Caixa", a través de la Obra Social, mencionan que, cuando les llegan solicitudes de financiación y donaciones, muchas veces estas peticiones no vienen acompañadas de un informe detallado que asegure que la cantidad aportada ha sido usada eficientemente para la finalidad que se había marcado. A través de este informe Gavi podía asegurar a "la Caixa" -y esta, a su vez, a sus clientes- que de cada euro que Gavi recibía se usaban 0,97 céntimos en la adquisición de vacunas para la Alianza.

Para facilitar la redacción del informe Gavi pidió a "la Caixa" que decidiera focalizar sus aportaciones en un país al que ayudar y en una enfermedad que atacar. Tras un periodo de reflexión se decidió que era de interés estratégico para "la Caixa" que sus aportaciones fueran utilizadas en Mozambique para combatir la neumonía. Las razones para esa decisión fueron varias. Además, significaba atacar la neumonía, que era una de las principales causas de mortalidad infantil en África, y seguir trabajando en alcanzar el tercero de los Objetivos de Desarrollo Sostenible (garantizar una vida sana y promover el bienestar para todos en todas las edades). La elaboración del informe fue un hito importante para "la Caixa" y también lo fue para la Alianza. Era la primera vez que Gavi presentaba a un socio una serie de opciones para orientar su donación y, en consecuencia, dejar que el donante participara en la decisión de en qué vacuna trabajar dentro del programa de la vacunación infantil, lo cual marcaba un precedente importante para la Alianza en relación con el sector privado. 
Durante la fase pasada ya se había empezado a desarrollar otra línea de trabajo en la estrategia de donaciones. Desde 2011 la Fundación Bill y Melinda Gates, junto con el Gobierno británico, venía realizando lo que se denominó el Matching Fund para incentivar las aportaciones privadas, incluidas las aportaciones de "la Caixa". La idea era sencilla: por cada euro que se donaba, la Fundación Gates lo duplicaba. "La Caixa”, que había fijado para 2013 una aportación de un millón de euros, vio en esa política una oportunidad para visibilizar la Alianza de manera más estratégica y así poder conseguir mayores aportaciones. Por lo tanto, en 2015 se decidió adoptar la estrategia de comunicación del Matching Fund en "la Caixa”, con la diferencia de que, al realizar una aportación, el efecto se multiplicaba. "La Caixa" se comprometía a doblar cada euro que fuese recaudado y la Fundación Bill y Melinda Gates, a su vez, duplicaría esa cantidad, de modo que cada euro inicial se convertiría en cuatro. Así se originó la campaña "1=4" (Figura 4). Las aportaciones que se habían recibido hasta entonces quedaban dentro del rango de un millón de euros, que era la cantidad que "la Caixa" tenía previsto aportar. Sin embargo, los resultados sobrepasaron las expectativas y para el cierre de 2018 lo recaudado estaba por encima de los dos millones de euros, por lo que "la Caixa" acabó duplicando la aportación directa inicial prevista.

Jordi Casajoana, director de Colectivos de Valor y Filantropía en CaixaBank, valoraba así esta iniciativa: "Lo que da un apoyo adicional muy claro, aparte de la calidad del proyecto, es el hecho de que entre la Fundación Gates y la Fundación "la Caixa” multipliquen por cuatro las aportaciones de los clientes. Creo que este es un argumento muy sólido. Cuando a un cliente le tienes que hablar de posibilidades de donación y le puedes explicar una opción que no solo es transparente, sino que también da medida de su impacto, que funciona, que es innovadora y que además con esa multiplicación por cuatro va a ser más eficiente para él, escoge esta causa, evidentemente".

Figura 4. Campaña $1=4$

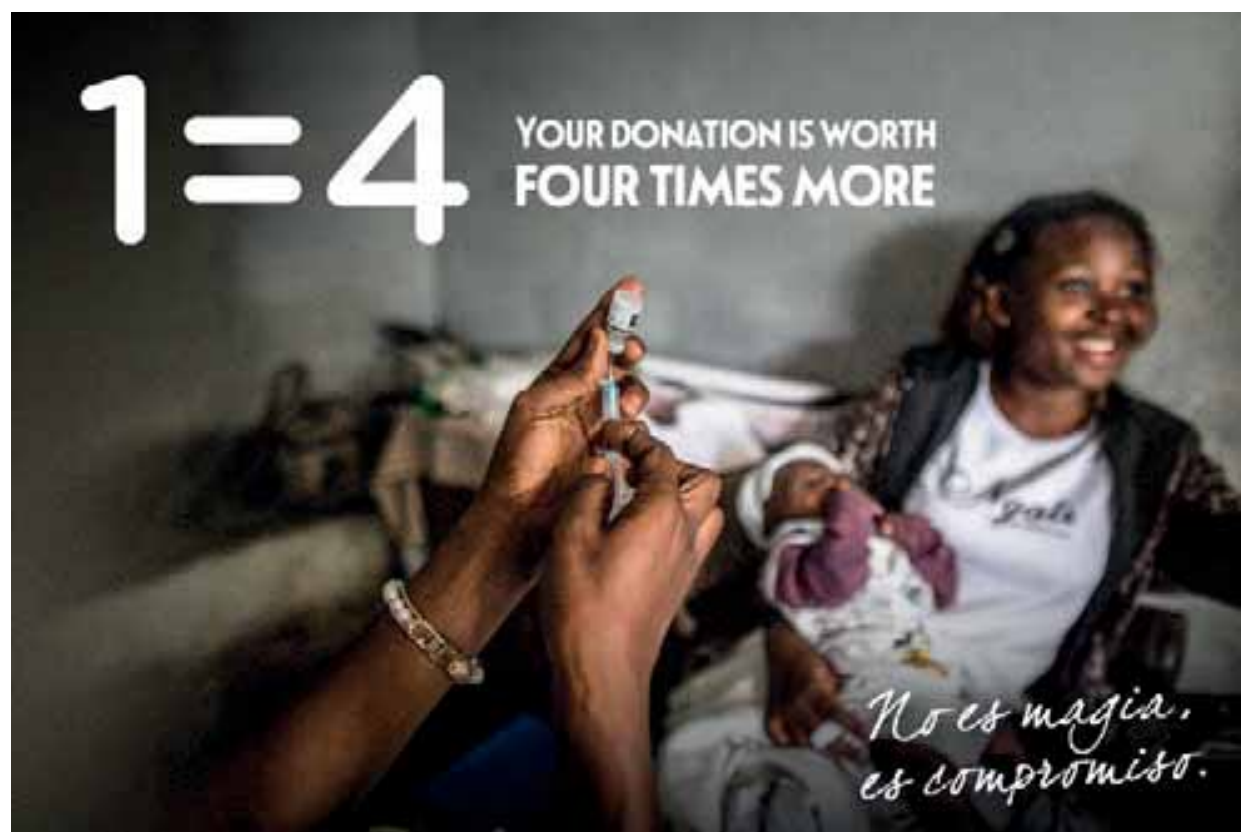

Los resultados de estas estrategias fueron importantes para la Alianza infantil. El número de empresas se multiplicó por dos entre 2015 y 2018, pasando de 205 a 562. El número de clientes de Banca Privada pasó de 115 en 2015 a 3.426 en 2018. El número de empleados se mantuvo en su media, mientras que el número de microdonaciones pasó de 11.636 en 2015 a 61.799 el 2018. En total, la cantidad recaudada se triplicó entre 2015 y 2018, pasando de 627.923 en 2015 a 2.017.783 en 2018.

En el Anexo presentamos dos tablas con los aportes de "la Caixa" durante todo el periodo de 2008 a 2011 y tres gráficos comparativos del total de aportaciones directas de "la Caixa", las recaudadas, el número de aportaciones y las aportaciones en euros. 


\section{Retos para el futuro}

Han sido 12 años de aportaciones sostenibles que no solo han logrado vacunar a niños en riesgo, sino que también han fortalecido la identidad de los colaboradores que han participado en la Alianza. Sin embargo, la pregunta sobre cómo podemos continuar mejorando está en el horizonte. Ariadna Bardolet, directora del departamento de Programas Internacionales en la Fundación "la Caixa”, se pregunta: “¿Cómo seguir incrementando el número e importe de las aportaciones de "la Caixa”? ¿Será posible? Si no lo es, ¿cómo podemos seguir aportando a la Alianza para la Vacunación Infantil?”. Una posibilidad es el proyecto INFUSE $^{14}$, que se encarga de ver nuevas e innovadoras formas de colaborar y contribuir con Gavi. Otra alternativa es continuar manteniendo el soporte a ISGlobal ${ }^{15}$ en el campo del conocimiento técnico y su traslación, como apuntaba Antoni Plascencia, director general de ISGlobal.

Por otro lado, la involucración de CaixaBank había demostrado ser clave durante estos años, así que se trataba de ver cómo seguir manteniendo efectiva la colaboración de las áreas de Banca de Empresas y Banca Privada. Ambas áreas tienen sus propias estrategias de acción social y con ello trabajan en la diversificación de las causas en las que implicarse, por lo que Gavi no es el único proyecto que tienen en cartera. Además, desde el punto de vista de responsabilidad corporativa de CaixaBank, el programa tiene otros frentes también. Meritxell Ripoll, en la actualidad directora de Responsabilidad Corporativa de CaixaBank, comenta que fue un acierto el hecho de que "se trataba de aplicar prácticas comerciales que utilizamos para ayudar en la venta de un producto comercial bancario a un tema que no lo era". El reto más importante era lograr que Gavi formara parte de una estructura de retos de negocio y pudiera convivir bien dentro de ella. El tema ahora es: ¿cómo lograr que esa convivencia sea sostenible en el tiempo?

La colaboración con Gavi encajaba bien con el interés de alinear las acciones de responsabilidad social con los Objetivos de Desarrollo Sostenible. Se mencionaban los objetivos número 3 (garantizar una vida sana y promover el bienestar para todos en todas las edades), 10 (reducir la desigualdad en y entre países) y 17 (revitalizar la Alianza Mundial para el Desarrollo Sostenible). La pregunta que se planteaba era si se debería pensar en la manera de reproducir el proyecto en otros países y con otras vacunas. De ser así, ¿cómo se haría? Además, estaba el nivel de identificación que existía con el proyecto. Ángel Ibáñez, coordinador y gestor de Banca Privada en una oficina de CaixaBank de Barcelona, indicaba que trabajar en este tipo de proyectos era una vocación dentro del trabajo diario. Sin embargo, ¿cómo podría mantenerse este nivel de identificación? ¿Y qué ocurriría con los clientes donantes? ¿Podría mantenerse el nivel de compromiso logrado hasta ahora?

Magdalena Robert, responsable principal de Programas en la Fundación Bill y Melinda Gates, consideraba que el reto estaba en cómo reproducir el modelo. En este sentido, comentaba lo siguiente: "Es muy interesante ver cómo el modelo generado por "la Caixa" junto con Gavi ha creado conciencia social en distintas instituciones y puede ser imitado". De igual manera estaba en el aire la expectativa de Gavi de seguir trabajando con "la Caixa". Así lo manifestó Seth Berkley, CEO de Gavi, al comentar esta colaboración: "As our first private sector partner, "la Caixa" has been an invaluable part of the Vaccine Alliance for over a decade. "La Caixa" has helped us reach more than 760 million children with lifesaving vaccines since 2000, saving 13 million lives, and helped us leverage innovative solutions to improve vaccine delivery in the world's poorest countries. I hope that we will continue to work closely together as Gavi aims even higher, looking to reach more than 1.1 billion children with vaccines by 2025".

\footnotetext{
${ }^{14}$ El proyecto INFUSE es interesante de analizar, ya que es una iniciativa de Gavi que ayuda a mejorar el sistema de distribución de las vacunas al conectar innovaciones de alto impacto con los países que más lo necesitan. Comprende cuatro pasos: la convocatoria para innovaciones, la comunidad INFUSE, el taller donde anualmente los participantes presentan sus innovaciones a un panel especializado, y los INFUSE Pacesetter, que son las propuestas seleccionadas. Precisamente, la distribución es uno de los puntos estratégicos en el nuevo planteamiento de Gavi con miras al 2025.

${ }^{15}$ ISGlobal es miembro de la Alianza para la Vacunación Infantil junto con "la Caixa”. Ha estado presente desde el inicio del proyecto en 2008 y se encarga de explicar los detalles del conocimiento técnico de las vacunas que son financiadas con el aporte de "la Caixa". Desde 2014 se encarga de otorgar los certificados de donación a todos los aportantes de la Alianza a través de "la Caixa". El papel de ISGlobal no es simplemente de apoyo administrativo, sino que su experiencia en el tema de la inmunización lo ha llevado a explicar en varias ocasiones el proyecto con Gavi a los clientes de "la Caixa".
} 


\section{Conclusión: las guías para una donación sostenible}

La Alianza para la Vacunación Infantil presenta un caso único donde el sector privado se une a una causa gestionada por una organización civil y el sector público. La colaboración de "la Caixa" con Gavi durante 12 años de aportaciones sostenibles ha tenido excelentes resultados, que no han estado exentos de dificultades, pero que se han sabido resolver con propuestas novedosas, integrando la razón de ser de la existencia de "la Caixa" y su Obra Social con las exigencias propias de una institución financiera para apoyar la misión de Gavi. Hasta diciembre de 2019 se había vacunado a más de 6,3 millones de niños en el mundo con las aportaciones realizadas y recaudadas por "la Caixa".

No es habitual encontrarnos con este tipo de casos, en los que una institución echa mano de su fuerza comercial para lograr un objetivo que no está relacionado directamente con los resultados financieros propios. Cabe resaltar que la historia de "la Caixa" desde sus orígenes hasta el día de hoy tiene un papel protagonista en este éxito. Sin embargo, existen ciertos pasos que se han desarrollado dentro de este caso que pueden ser reproducidos por otras organizaciones privadas que quieran colaborar tanto con Gavi como con cualquier otra entidad con una fuerte misión colectiva que necesite de la colaboración de miembros de la sociedad civil.

Muchos de los problemas que la sociedad tiene que resolver son habitualmente demasiado complejos para ser abordados de forma individual. La clave para poder enfrentarse a ellos de la mejor manera posible es unir fuerzas con otras organizaciones e instituciones, incluso con aquellas que puedan ser muy diferentes. Eso es lo que persigue el Objetivo de Desarrollo Sostenible número 17 cuando reclama el compromiso decidido a favor de alianzas mundiales y la cooperación entre agentes sociales.

En este caso hemos presentado el éxito de la colaboración de una entidad financiera como "la Caixa" con el proyecto de Alianza para la Vacunación Infantil de Gavi. De su estudio podemos identificar cinco guías que son la base y el motor para afrontar con éxito una iniciativa parecida a la descrita (Figura 5):

1. Determinar un objetivo focalizado y concreto: muchas donaciones ofrecen una idea general de por qué necesitan ayuda. En el caso vemos como "la Caixa" fue transparente al solicitar un informe y fue Gavi quien para poder hacerlo le requirió, a su vez, que decidiera de manera más concreta donde canalizar sus aportaciones, reduciendo el ámbito de su ayuda a un país y una enfermedad. Este objetivo concreto es fácil de identificar y de cuantificar, por lo que genera sentido de pertenencia e identidad para los diferentes agentes implicados.

2. Informar de los resultados con detalle: comunicar siempre los resultados de la donación. Al hacerlo no solo se está asegurando que la donación recaudada esté siendo utilizada eficientemente, sino que se da una imagen de transparencia que genera confianza. Reforzar la relación con los donantes es de vital importancia. Realizar informes fortalece la confianza y estrecha las relaciones que se tienen con los donantes. En este caso, vemos como Gavi y "la Caixa” informan sobre sus donaciones con todo detalle, además de que ambas instituciones auditan externamente sus programas.

3. Equiparar la donación con un producto: al recaudar donaciones cuando ello no forma parte del negocio central, la manera más efectiva de comprometer a los empleados en la recaudación es dejar en claro que para la organización el paquete de donación es tan importante como cualquier otro de los productos que la compañía tiene. Es recomendable no realizar diferencias entre la oferta de un paquete de donación y un paquete de productos comerciales. Los colaboradores y clientes necesitan saber que para la organización la donación es tan importante como las ventas; ello incrementa el compromiso y refuerza los vínculos entre la entidad, los clientes y los colaboradores.

4. Diseñar y utilizar incentivos no monetarios: ofrecer la experiencia directa en lugar del incentivo monetario: para generar mayor empatía y sensibilidad con la causa es más apropiado utilizar incentivos no monetarios. En este caso, dentro de estos incentivos, se han ofrecido la experiencia directa con la causa que se estaba apoyando y el reconocimiento público a los colaboradores que conseguían el mayor número de aportaciones. Cuando el colaborador se identifica con el proyecto de manera directa aumenta su compromiso con el mismo y se convierte en un agente transformador dentro de la misma empresa. 
5. Ser ejemplo y comunicarlo efectivamente: si se quiere que otras organizaciones también empiecen a donar, la organización debe ser la primera en hacerlo, es decir, ser el ejemplo en primera instancia y luego solicitar a otras organizaciones sumarse al esfuerzo que se está realizando. Pedir donaciones cuando uno también lo está haciendo generará mayor empatía e incrementará la cantidad recaudada. Además, será bueno comunicar todos los esfuerzos de manera estratégica. La razón no es tanto incrementar la reputación como generar empatía con el esfuerzo que se está realizando para generar mayores recaudaciones. En este punto son esenciales las habilidades para comunicar. Nadie se identifica con una organización que comunica sus aciertos si se sospecha que lo hace para incrementar su propio ego; en cambio, sí resulta efectivo cuando se percibe que se hace con la buena intención de generar un efecto multiplicador en la donación.

Figura 5. Los motores de la donación sostenible

\section{Objetivo 17: Alianzas para lograr los objetivos}

Focalizar los objetivos

Informar al detalle

Equiparar la donación

Incentivos no monetarios

Hacer y decir

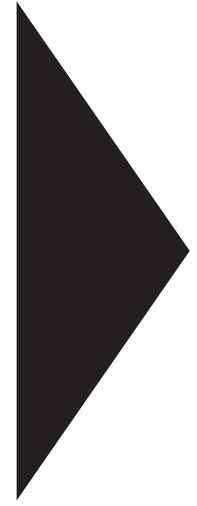

\section{Donación} sostenible 


\section{Anexos}

Tabla 1. Donaciones de “la Caixa” de 2008 a 2013

\begin{tabular}{|c|c|c|c|c|c|c|}
\hline $\begin{array}{c}\text { ALIANZA PARA LA } \\
\text { VACUNACIÓN INFANTIL }\end{array}$ & 2008 & 2009 & 2010 & 2011 & 2012 & 2013 \\
\hline Empresas & 95 & 62 & 26 & 35 & 88 & 161 \\
\hline Donaciones de empresas & $267.850 €$ & $182.650 €$ & $166.200 €$ & $228.850 €$ & $267.750 €$ & $361.250 €$ \\
\hline Particulares & 52 & 38 & 27 & 16 & 30 & 19 \\
\hline Donaciones de particulares & $11.382 €$ & $6.410 €$ & $516 €$ & $1.370 €$ & $780 €$ & $2.611 €$ \\
\hline \multicolumn{7}{|l|}{ Clientes de Banca Privada } \\
\hline \multicolumn{7}{|l|}{ Donaciones de clientes de Banca Privada } \\
\hline Empleados & 269 & 550 & 727 & 741 & 742 & 736 \\
\hline Donaciones de empleados & $9.539 €$ & $41.346 €$ & $47.616 €$ & $47.848 €$ & $49.798 €$ & $51.979 €$ \\
\hline \multicolumn{7}{|l|}{ Microdonativos } \\
\hline \multicolumn{7}{|l|}{ Donaciones de microdonativos } \\
\hline Total de donaciones recibidas & $288.771 €$ & $230.406 €$ & $214.332 €$ & $278.068 €$ & $318.328 €$ & $415.840 €$ \\
\hline $\begin{array}{r}\text { Aportación total de la Fundación } \\
\text { Bancaria "la Caixa" }\end{array}$ & $4.000 .000 €$ & $4.000 .000 €$ & $3.000 .000 €$ & $2.000 .000 €$ & $2.000 .000 €$ & $1.000 .000 €$ \\
\hline Aportación total a Gavi & 4.288.771€ & $4.230 .406 €$ & $3.214 .332 €$ & $2.278 .068 €$ & $2.318 .328 €$ & $1.415 .840 €$ \\
\hline
\end{tabular}

Fuente: Elaboración propia basado en información proporcionada por la Fundación “la Caixa”.

Tabla 2. Donaciones de “la Caixa” de 2014 a 2019

\begin{tabular}{|c|c|c|c|c|c|c|c|}
\hline $\begin{array}{l}\text { ALIANZA PARA LA } \\
\text { VACUNACIÓN INFANTIL }\end{array}$ & 2014 & 2015 & 2016 & 2017 & 2018 & 2019 & $\begin{array}{c}\text { Total } \\
(2008-2019)^{1}\end{array}$ \\
\hline Empresas & 124 & 205 & 280 & 385 & 562 & 814 & 2.836 \\
\hline Donaciones de empresas & $367.100 €$ & $467.396 €$ & $498.679 €$ & $661.109 €$ & $917.500 €$ & $1.161 .388 €$ & $5.546 .721 €$ \\
\hline Particulares & 6 & 5 & 4 & 23 & 6 & 4 & 231 \\
\hline Donaciones de particulares & $125 €$ & $420 €$ & $200 €$ & $2.725 €$ & $4.090 €$ & $632 €$ & $32.261 €$ \\
\hline Clientes de Banca Privada & & 115 & 195 & 1.600 & 3.426 & 2.660 & 7.996 \\
\hline Donaciones de clientes de Banca Privada & & $34.823 €$ & $67.397 €$ & $438.810 €$ & $946.764 €$ & $716.103 €$ & $2.203 .897 €$ \\
\hline Empleados & 738 & 753 & 756 & 762 & 760 & 754 & 8.288 \\
\hline Donaciones de empleados & $46.805 €$ & $46.826 €$ & $47.125 €$ & $44.982 €$ & $44.731 €$ & $43.756 €$ & $522.351 €$ \\
\hline Microdonativos & 11.636 & 29.880 & 75.695 & 60.315 & 61.799 & 50.821 & 290.146 \\
\hline Donaciones de microdonativos & $43.661 €$ & $78.458 €$ & $131.569 €$ & $126.864 €$ & $104.198 €$ & $84.289 €$ & $569.039 €$ \\
\hline Total de donaciones recibidas & $457.691 €$ & $627.923 €$ & $744.970 €$ & $1.274 .490 €$ & $2.017 .283 €$ & $2.006 .168 €$ & $8.874 .269 €$ \\
\hline $\begin{array}{r}\text { Aportación total de la Fundación } \\
\text { Bancaria "la Caixa" }\end{array}$ & $1.000 .000 €$ & $1.000 .000 €$ & $1.000 .000 €$ & $1.274 .490 €$ & $2.017 .283 €$ & $2.000 .000 €$ & 24.291.773€ \\
\hline Aportación total a Gavi & $1.457 .691 €$ & $1.627 .923 €$ & $1.744 .970 €$ & $2.548 .980 €$ & $4.034 .566 €$ & $4.006 .168 €$ & $33.166 .043 €$ \\
\hline
\end{tabular}

Fuente: Elaboración propia basado en información proporcionada por la Fundación "la Caixa".

${ }^{1}$ En "Empresas", "Particulares", “Clientes de Banca Privada”, "Empleados” y “Microdonativos", un mismo donante puede haber repetido en diferentes años. 
Figura 1. Donaciones realizadas directamente y recaudadas por "la Caixa"

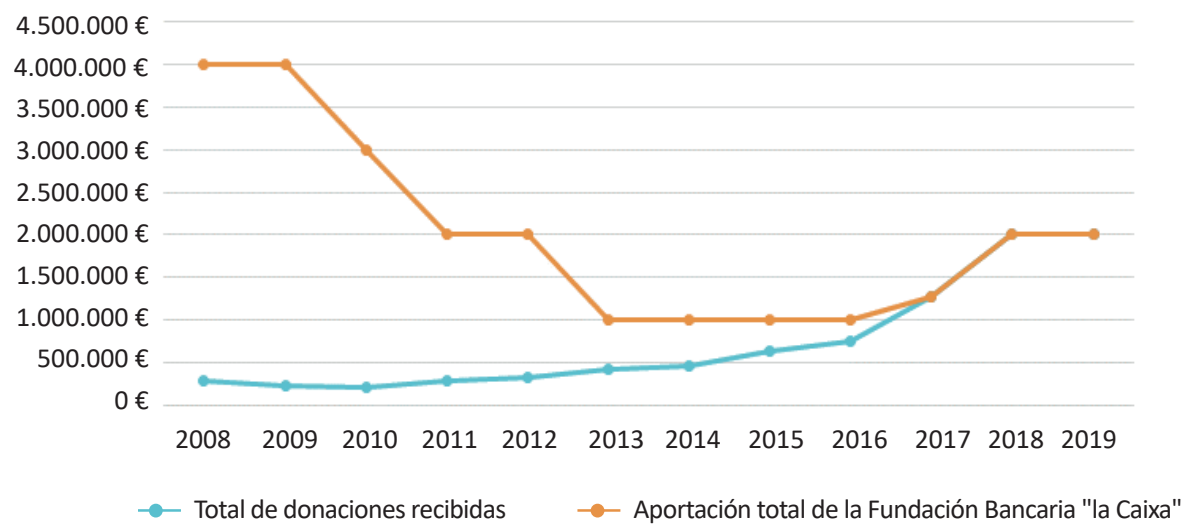

Fuente: Elaboración propia basado en información proporcionada por la Fundación "la Caixa".

Figura 2. Comparación de donaciones: número

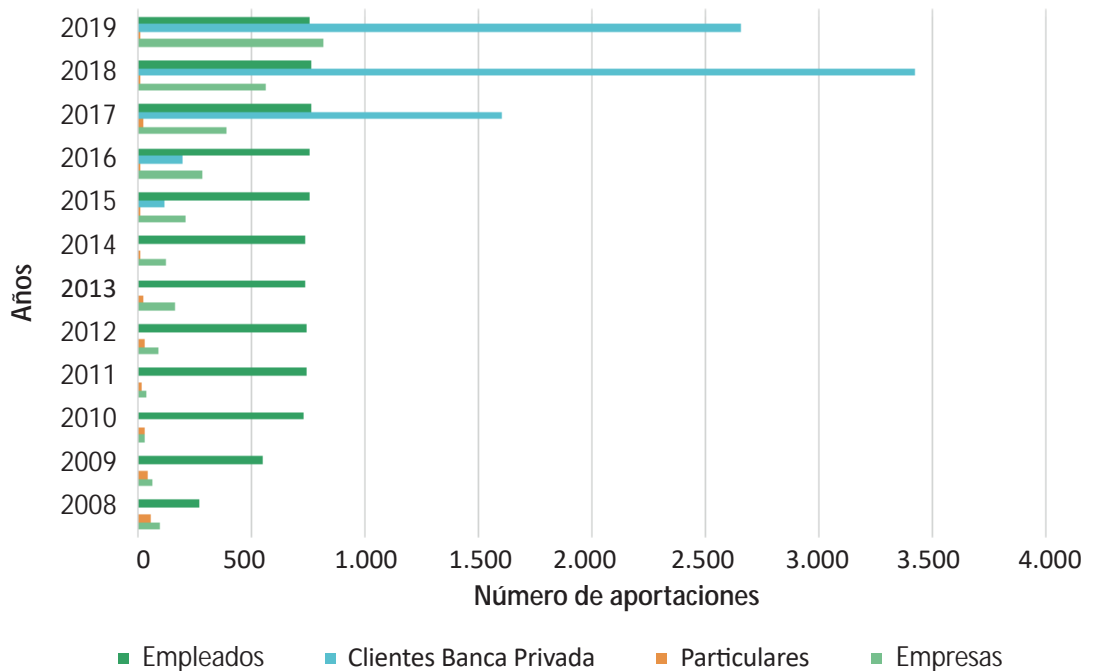

Fuente: Elaboración propia basado en información proporcionada por la Fundación "la Caixa".

Figura 3. Comparación de donaciones: importe

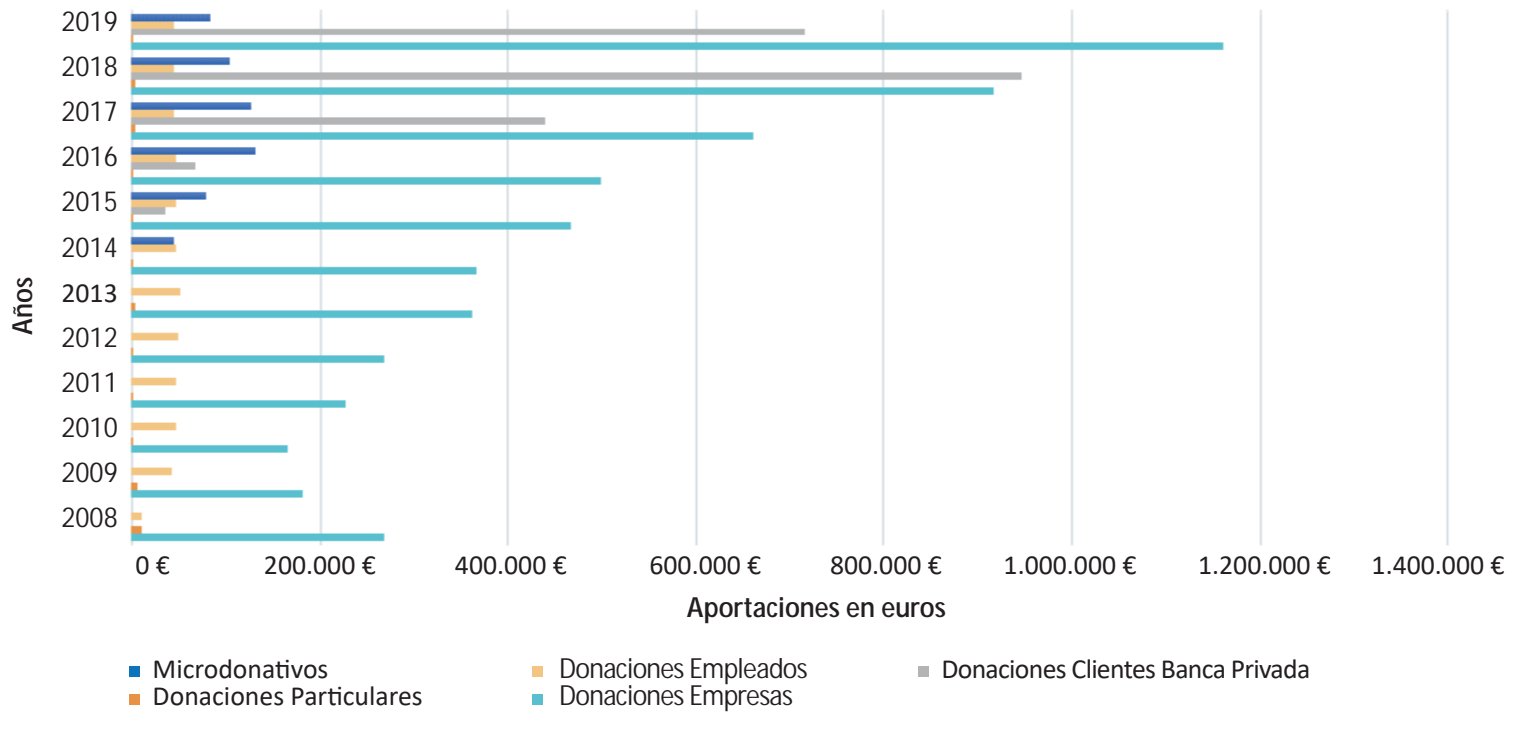

Fuente: Elaboración propia basado en información proporcionada por la Fundación "la Caixa". 


\section{: \\ Business School \\ University of Navarra}

A Way to Learn

A Mark to Make

A World to Change

Follow us

(in) IESE Business School

f IESE Business School

(7) iesebs

Yout iese

\section{Barcelona}

Av. Pearson, 21

08034 Barcelona, Spain

(+ 34) 932534200
Madrid

Camino del Cerro

del Águila, 3

28023 Madrid, Spain

(+34) 912113000
New York

165 W. 57th Street

New York,

NY 10019-2201 USA

(+1) 6463468850
Munich

Maria-Theresia-Straße 15

81675 Munich, Germany

(+49) 8924209790
Sao Paulo

Rua Martiniano de

Carvalho, 573

Bela Vista

01321001 Sao Paulo, Brazil

(+55) 1131778221 